\title{
Das Europäische Wirtschaftsrecht vor neuen Herausforderungen
}

Beiträge aus Deutschland und Griechenland

Hrsg. v. Klaus J. Hopt u. Dimitris Tzouganatos

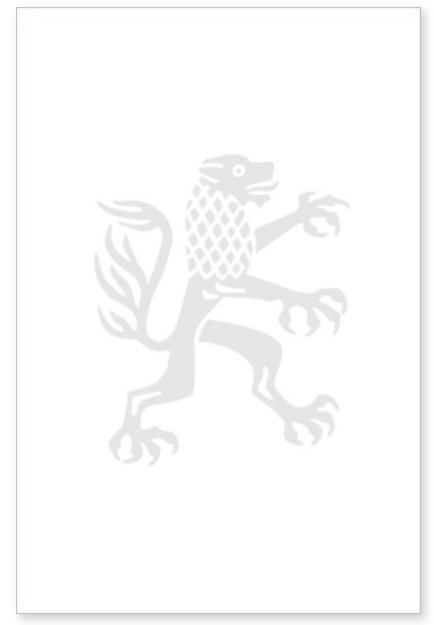

2014. XIX, 355 Seiten. BtrIPR 108

ISBN 978-3-16-153765-3

DOI 10.1628/978-3-16-153765-3

eBook PDF $104,00 €$

ISBN 978-3-16-153635-9

Leinen $104,00 €$
Das Europäische Wirtschaftsrecht steht nach der Finanzkrise vor ganz neuen Herausforderungen. Seither ist ein »Tsunami« europäischer Rechtssetzungsvorschläge und Rechtssetzungsakte auf die Mitgliedstaaten herniedergeprasselt, denen sich die Praxis und Wissenschaft stellen müssen. Die Probleme und Auswirkungen sind in den Mitgliedstaaten teilweise gleich, teilweise unterschiedlich. Deshalb wird prototypisch Deutschland als ein eher »nördliches « Land und Griechenland als ein »südliches« Land unter dem Thema der Rechtsangleichung auf dem Gebiet des Wirtschaftsrechts untersucht. Dabei geht es konkret um die europäische Bankenunion, die Bankenrestrukturierung, das europäische Gesellschafts- und Kapitalmarktrecht, europäisches Privat- und Verbraucherschutzrecht, europäisches Prozessrecht, Wettbewerbs- und Kartellrecht bis hin zur europäischen Wettbewerbspolitik.

Inhaltsübersicht

\section{Europäisches Bank- und Finanzrecht}

Jens-Hinrich Binder: Auf dem Weg zu einer europäischen Bankenunion. Erreichtes, Unerreichtes, offene Fragen - Georgios Psaroudakis: Das Recht der Bankenrestrukturierung in Zeiten der Wirtschaftskrise

II. Europäisches Gesellschafts- und Kapitalmarktrecht

Rüdiger Veil: Kapitalmarktgesetzgebung im Zeitalter der ESMA. Europa auf dem Weg in die Kapitalmarktunion - Christoph Kumpan: Interessenkonflikte von Organverwaltern. Zur Dogmatik der Fremdinteressenwahrung im Gesellschaftsrecht -

Nikolaos A. Vervessos: Das naming and shaming als Sanktion gegen kapitalmarktrechtliches Fehlverhalten

III. Europäisches Privatrecht

Karl Riesenhuber: Auf dem Weg zu einem europäischen Privatrecht - Antonios G. Karampatzos: Rechtspaternalismus im Europäischen Verbraucherschutzrecht. Lehren aus »Behavioural Law and Economics« - eine Bestandsaufnahme IV. Europäisches und internationales Prozessrecht

Jan von Hein: Wirtschaftsrechtlich bedeutende Neuerungen in der Europäischen Gerichtsstands- und

Vollstreckungsverordnung von 2012. Gerichtsstandsvereinbarungen und Abschaffung des Exequaturs - Georgios Orfanidis: Die Verordnung (EU) Nr. 655/2014 des Europäischen Parlaments und des Rates über ein europäisches Verfahren zur vorläufigen Kontenpfändung V. Regulierung durch Privatrecht

Tobias Tröger: Regulierung durch Privatrecht. Folgenorientierung in der Privatrechtswissenschaft als Konsequenz latenter oder intendierter Verhaltenssteuerung durch privatrechtliche Normen

VI. Wettbewerbs- und Kartellrecht

Emmanuela Truli: Wettbewerbsrechtliche Problemstellungen aus der Aktionärsrolle des Staates in mehreren Banken am Beispiel Griechenlands - Friedemann Kainer: Auf dem Weg zu einer einheitlichen europäischen Wettbewerbspolitik

Klaus J. Hopt ist Direktor emeritus des Max-Planck-Instituts für ausländisches und internationales Privatrecht in Hamburg und Professor emeritus an der Universität Hamburg; vormals Richter am OLG Stuttgart.

Dimitris Tzouganatos ist Professor an der Juristischen Fakultät der Nationalen Universität Athen und Rechtsanwalt.

Jetzt bestellen:

https://mohrsiebeck.com/buch/das-europaeische-wirtschaftsrecht-vor-neuen-herausforderungen-9783161537653? no_cache=1

order@mohrsiebeck.com

Telefon: +49 (0)7071-923-17

Telefax: $+49(0) 7071-51104$ 